NBER WORKING PAPERS SERIES

CONTRACTS AND THE MARKET

FOR EXECUTIVES

Sherwin Rosen

Working Paper No. 3542

NATIONAL BUREAU OF ECONOMIC RESEARCH 1050 Massachusetts Avenue

Cambridge, MA 02138

December 1990

This paper was prepared for Nobel symposium No. 77 : Contracts:

Determinants, Properties and Implications, Stockholm, August $18-$ 20, 1990. This paper is part of NBER's research program in Labor Stucies. Any opinions expressed are those of the author and not those of the National Bureau of Economic Research. 
NBER Working Paper \#3542

December 1990

\title{
CONTRACTS AND THE MARKET FOR EXECUTIVES
}

\begin{abstract}
ABETRACT
The paper reviews empirical findings on executive compensation in light of marginal productivity and contract theories. The executive labor market performs three functions. First, control must be distributed and assigned among executives. The most talented executives are efficiently assigned to control positions in the largest firms when talent and the marginal product of control are complements. These gains or rents are partially captured in larger earnings. In fact, the elasticity of top executive pay lies within a tight band around .25 among industries, time periods, and countries where it has been estimated. second, executive contracts must provide incentives for managers to act in the interests of shareholders. Potential loss of reputation, bonding and takeovers probably substitute for direct monetary incentives in this task. Nevertheless, the elasticity of top executive pay with respect to accounting rates of return lie near 1.0. The elasticity with respect to stock market returns is much smaller, though precisely estimated, near 0.1 . Differences of opinion remain on whether the market provides enough incentives to align interests between ownership and control. Third, the market must identify new talent and reassign control over careers from older to younger generations. Competition among executives for top positions and the diminishing incentive effect of future rewards with age implies that compensation should increasingly tilt rewards to current performance over the course of a career. Available evidence supports this prediction.
\end{abstract}

Sherwin Rosen

Department of Economics

University of Chicago

Chicago, Illinois 60637 


\section{CONTRACTS AND THE MARKET FOR EXECUTIVES}

Sherwin Rosen*

University of Chicago

\section{INTRODUCTION AND SUMMARY}

The vital function of business executives in efficiently directing the vast amounts of resources under their control makes the executive labor market an especially interesting one to study. Berle and Means raised the fundamental contractual issue by pointing out possible conflicts of interest arising from separation of ownership and control. It has taken many years for the economics profession to put these matters in proper perspective.

The first important response was to identify a market for corporate control [Manne (1965)], whereby the threat of involuntary termination would provide incentives for managers to align their actions with shareholders' interests. The remarkable level of activity in the American corporate-control market in recent years has dispelled any lingering doubts about the importance of this mechanism. Still, there remain differences of informed opinion on its efficacy for solving the problem.

Second generation debates on the managerial theory of the firm [Marris (1963), Baumol (1967)] focused attention on the firm's objective function. If managers operated the firm in shareholders' interests then they would maximize profits, and if they catered to their own interests then such things as sales and the amount of assets controlled would enter into the firm's objectives. An empirical question was immediately suggested: did executive earnings respond more to profitability or to sales? The Paper prepared for Nobel Symposium No 77: Contracts: Determinants, Properties and Implications, Stockholm, August 18-20, 1990. 
investigations provoked by this question were among the first empirical studies of agency.

It would be interesting to report that these studies provided empirical basis for the extensive theory of agency that has been developed recently, but that is not the way it happened. Rather, much of that development paralleled theoretical research on information economics. Whatever its source, the executive labor market is one of the most importan: practical applications of the new theory. Theory in turn has provided a useful framework for thinking about the data and for showing precisely how various mechanisms may be devised to align the interests of control and ownership. I attempt to join the theoretical and empirical strands of this literature in this paper. It is organized around the three main economic problems that the executive labor market must solve: the distribution and assignment of control among executives; providing performance incentives; and identifying talent and reassigning control in the course of career development.

Section II briefly takes up the problem of the allocation of control, given incentives. The idea is that personal power and influence in an organization depend on the interactions between talent and the productivity of control. If there is complementarity between the two it is efficient to assign greater control to more talented persons. In a market equilibrium, the most talented executives occupy top positions of the largest firms, where the marginal productivity of their actions is greatly magnified over the many people below them to whom they are linked. This explains why earnings of top executives in large firms are so large, and why executive pay is positively correlated with firm size. The empirical 
elasticity of top executive pay with respect to firm size is approximately .25 for all industries and time periods for which it has been estimated. Sections III and IV take up the agency-incentive question, given the allocation of control. Theory predicts that the structure of pay strikes a compromise between incentives and insurance. Much evidence supports that prediction. The direct incentive component is of particular interest. The elasticity of compensation with respect to accounting rates of return is in excess of 1.0 ; and the elasticity with respect to the stock market rate of return is approximately .10. However, there exists no theoretical benchmark to serve as a guide for what size number should be expected, and disputes remain on whether compensation mechanisms provide enough incentives to elicit efficient management behavior.

Section $V$ joins the assignment and incentive questions. How are competent and talented managers identified and how is control reallocated over the course of careers across successive, over-lapping generations? For this task the labor market must keep a running score on available talent and adjust the assignment of control accordingly. Competition is thereby induced among contenders to influence the scoring process and gain greater rank and control over their careers. Such competition, of which promotion to higher paying and more responsible positions is an important part, is the means by which control is transferred across the generations. Career incentives serve as better substitutes for current performance incentives at earlier stages of a career than in later stages, when a rapidly diminishing horizon reduces any incentive effects of future status on current behavior. Available data support the idea that compensation is increasingly structured to reward and weigh current performance more heavily over the course of a career, as theory suggests. 
The final section draws out some suggestions for further work.

\section{THE MARGINAL PRODUCTIVITY THEORY}

Great power to direct resources and the large earnings that go with it are what make the executive labor market so interesting. Power and income are related in a market economy, where remuneration is proportional to one's marginal contribution to production. Early work began to connect marginal productivity to business decisions within hierarchical control structares - see Reder's (1968) excellent survey for references. Activities of top management are magnified geometrically because they affect recursively the productivity of all who work below them in the organization. This "scale of operations" effect, multiplying little bits over each of many units, accrues to the more talented managers as economic rent in a competitive equilibrium, much like a "superstar" effect [Rosen (1981)].

Top management inputs have much in common with local public goods. consisting as they do of commands and decisions affecting the productivity of the organization as a whole. What type of goods should be built and on what scale? What niche should the firm play in the market and how should its products be priced? Although a detalled theory of the division of labor in management organization is unavallable, a simple hierarchical model illustrates the essence of the idea (see Rosen (1982) and Miller (1982) for more details].

\section{A. The Model}

Consider a hierarchy with a fixed span of control, s, throughout every branch. Then the organization is a strictly triangular tree with $s$ branches at every node. Production occurs at the bottom layer. Higher levels are exclusively devoted to "management" activities, which refine and 
augment production worker output. Decisions made at a higher level get dissipated somewhat in percolating down the tree, but link in a multiplicative way to more production workers and have larger marginal product the higher up they start.

Let $z$ be a worker's talent (measured as output in self-

employment). Assume that a level-j manager produces $\left(k z_{j}+m z z_{-1}\right)$ units of service jointly with each of the $s$ immediately subordinate workers below him, where $k$ and $m$ are positive constants independent of $j$ and $m+k<1$. Then a one management level firm produces output of $s\left(k z_{1}+m z_{0}\right)$. A two level firm produces $s^{2}\left(k\left(k z_{2}+m z_{1}\right)+m z_{0}\right)$ units, and by recursion an $n$. layer organization with $s^{n}$ production workers, produces output of

$$
\begin{aligned}
Y_{n} & =s^{n}\left(k^{n} z_{n}+k^{n-1} m z_{n-1}+\ldots+m z_{0}\right) \\
& =A^{n} z_{n}+\sum_{j=1}^{n-1} s^{n-j_{A} j_{m z}}+s^{n} m z_{0}
\end{aligned}
$$

where $j-0$ is the bottom production level layer, $j-n$ is CEO and $A=s k>1.0$ is the net span of control. From the second expression, the CEO contributes $A^{n} z$ to output, a j-level manager contributes $A^{j} m$ and a production worker contributes $m z$. That there is one CEO, $s^{n-j}$ level-j managers and $s^{n}$ production workers gives total production in the firm. The marginal product of talent is larger at higher levels of a hierarchy, through a chain letter-like effect. The CEO effectively is "cloned" (sk) $\mathrm{n}$ times through subordinates in the chain-of-command. Lower level managers are cloned only $(s k)^{j}$ times (for $j<n$ ) because their input 
has a shorter distance to travel down the tree and is further discounted (by $m<1$ ) arising from the need to spend time processing supervisors' orders. Let $w_{j}(z)$ be the wage of a level-j manager of talent $z$. Additivity of equation (1) implies that output is linear in talent within levels. Therefore, incremental product accrues as rent to talent within levels according to:

$$
w_{j}(z)-w_{j}+A^{j} m, \quad j-0,1, \ldots, n-1
$$

where $\left(w_{j}\right)$ are constants, determined by equating market supply and demand in the assignment of workers by talent to levels.

Total rent accruing to the person at the top of an $n$-level

organization is the difference between output and costs of lower level workers. Defining profits as revenue minus costs, using (2) and simplifying

$$
I_{n}(z)-A^{n} z_{n}-\sum_{j=0}^{n-1} s^{n-j_{w}}
$$

This too is linear in $z_{n}$. The first term can be interpreted as the unit toll the CEO collects for each of the $A^{n}$ times he is cloned through all subordinates. The second term is the payment the CEO must make to all level-j subordinates for that privilege while letting them collect their own ability rents through their subordinates.

The earnings-talent gradient is linear within levels in (2) and (3), but is highly nonlinear between levels because the market equilibrium assigns talents to positions along the upper envelope of (2) and (3). The envelope is strictly convex, following from the fact that the marginal 
product of talent is increasing in level in (1). Consequently, a competitive market allocates talented people to higher level positions in larger firms. Complementarity between talent and productivity inherent in hierarchical structures - $\partial Y_{n} / \partial z_{j}$ increasing in $j$ in (1) - is what makes this so. Scarce talents of the most capable managers are economized by assigning them to positions at or near the top of the largest firms, where their ability is magnified to greater effect by spreading it over longer chains-of-command and larger scales of operations. These magnification effects accrue to these executives as rent. This is what sustains high average earnings of top level executives in large firms and also implies that firm size and executive pay should be positively related. Since the firms we are concerned with here have average assets of $\$ 5 B$ and large numbers of employees and other stake-holders, multiplicative scale-ofoperations effects loom large: a little extra talent at the top can have enormous effects on total output. The social gain? to devising efficient incentive mechanisms and to identifying the most talented managers are likely to be correspondingly large.

B. The Evidence

Top executive salaries increase with the size of firm. Most of the evidence relates to the top five ex sutives of American corporations as reported, by law, in annual proxy statements to shareholders. Lower ranking executives have not been studied very much because no public data are available, though a few studies have used proprietary data on such persons. Most of the evidence on firm size and executive pay comes from empirical attempts to parcel out executive pay to firm size or growth "causes" on the one hand, and to the profitability of the firm on the other. The preceding analysis shows that such attributions of causes are 
conceptually ambiguous and not mutually exclusive because large firms are more likely to be headed by more able executives and this has little bearing on whether firms can be treated as sales or as profit maximizers. Unusual talents and abilities must earn scarcity rents even in the absence of agency and incentive problems.

Many of these studies have encountered multicollinearity problems Firms with large assets and sales revenues also have large accounting profits in absolute terms. The common factor, bigness, is at work. Even. in comparing a giant firm with a merely large one, the sheer effects of scale dominate comparisons in cross-firm salary regressions and often make the regressors colinear [Cisel and Carroll (1980), Dunlevy (1985)]. There is no "solution" to a multicollinearity problem and any way they are cut, scale effects show up powerfully in the data on top executive pay.

The numerous studies that bear on the relation between pay and the scale of resources controlled represent something of an empirical zoo. The main problem in assessing the evidence is that specifications vary widely from study-to-study. Multicollinearity plays some role here and so do such trivialities as different choice of units of measurement and $\log$ transforms without presenting enough sample information for readers to construct elasticities. A definitive study will be one that estimates all existing specifications on one consistent data source.

A start in this direction for scale effects appears in Kostiuk (1989). His own estimates are based on 73 large U.S. corporations over the 1969-81 period. The elasticity of executive annual-salary-plus-bonus with respect to sales of the firm is in the .2 to .25 range. Including firm. fixed effects does not change things. The elasticity is the same in the time-series "within" firm comparison as in the cross-section "between" firm 
comparison. A firm that is 10 percent larger than another on average pays its top executives 2.5 percent more; and when the latter firm grows by 10 percent, its top executives are on average paid 2.5 percent more in salary and bonuses. Murphy (1985) reports a similar estimate on a related sample, but using a broader definition of pay that includes deferred compensation and stock options: these components of pay are not very sensitive to size and scale variables. The regression specifications are sufficiently different between the two studies to suggest that the estimated elasticity is fairly insensitive to specification.

More convincing evidence comes from comparing studies that used much different data. Kostiuk's and Murphy's estimates are in the vicinity of Roberts' (1956) early estimate of .35 for selected manufacturing firms in the U.S. In the late 1940s and 1950. Using American data from 1937-39, Kostiuk (1989) finds an asset elasticity of .3, close to the .25 elasticity estimated on U.S. data in 1967-71. Furthermore, Cosh (1975) has estimated an asset elasticity of . 26 for Britain during 1969-71. This is remarkably close to that found for the United States. Barro and Barro (forthcoming) find an asset elasticity of .32 for CEOs of U.S. commercial banks in the 1980s. Even those studies for which elasticity cannot be computed [McGuire, et al. (1962), Winn and Shoenhair (1988), Ciscel and Carroll (1980) .. exceptions are Kokkelenberg (1988) and Lewellen and Huntsman (1970)] find strongly positive effects of sales or assets on executive pay.

The relative uniformity of the elasticity of executive pay with respect to scale across firms, industries, countries and periods of time is notable and puzzling because the technology which sustains control and scale should vary across these disparate units of comparison. Thus the uniformity of estimates is a little too good to be true. One suspects 
copycatting behavior among firms in compensation policy, yet the Conference Board compensation surveys that possibly provide the information for such comparisons group the data by industry. And copycat behavior cannot accoun: for the 1930s estimate because the data were scarcely available. It surely cannot extend from the U.S. to the U.K. comparison. A convincing explanation is an open question.

\section{INCENTIVE PAYMENTS}

Much of the recent interest in executive labor markets comes from new conceptual developments on incentive aspects of labor supply.

A. Pay and Hours of Work

High ranking executives in large corporations earn large amounts of money, averaging $\$ 500,000$ per year in salary and bonus alone. Adding deferred pay, options, and pensions sometimes changes it by more than one order of magnitude. Systematic data on the hours worked by high-ranking business. executives are not avallable, but much informal evidence indicates that both hours worked and the intensity of work are among the largest of any specific occupational group in the economy. There is no shortage of labor supply in the usual sense and in fact salaries are independent of hours worked. Apparently, self-regulation, peer pressure, and monitoring by superiors are adequate to maintain great work intensity and long hours.

B. Agency: Nature of the Problen

The interesting question is whether or not executive efforts are directed toward the proper goals. Do business managers and executives direct their work to serve the interests of shareholders and other stakeholders or do they use them in more self-serving ways? 
At heart this agency problem represents some limitation on possibilities for decentralizing the functions of management in market economies. Specialization of knowledge and information, and the capital requirements of large enterprises virtually dictate a managerial function that is itself speclalized and separated from ownership but tied to the fortunes of one enterprise. The resources controlled by such firms are so large that they must be assembled from far and wide. Individual owners cannot shepherd their resources in that way due to lack of skill, specific production and market knowledge, and motivation. Instead, they must place a certain amount of trust in a management team to take proper actions on their behalf. Herein lies the agency problem.

The formal problem is to design contracts to induce executives to act in their shareholders' interests. Various mechanisms have been identified that might accomplish this task. Economists have confined their attention to an idealized problem where the technology, scope for actions and outcomes are common knowledge among principals and agents and only the action taken is private information of the agent. Principals know a great deal about the business, including what actions should be taken conditional on circumstances. They simply don't know what circumstances arose in any given realization: only the agent knows that. This is a far more constrained view than the idea of Berle and Means or even that of the law on principal and agent relations, where the agent typically is hired to render services of exclusive technical or other specialized knowledge that cannot be known to principals because it is not their business. 


\section{Penalties for Misbehavior}

Incentive schemes can either penalize unwanted behavior (negative feedback) or reward desirable behavior (positive reinforcement). Ambiguity arises because rewards for good behavior imply, by lack of reward, penalties for poor behavior and is resolved by adopting some norm of "expected behavior." The earliest approaches to agency theory suggested penalties as efficient incentives [Mirrlees (1976)]. Diminishing marginal utility of money makes the monetary reward required to induce good behavior larger than the monetary penalty needed to discourage bad behavior.

1. Bonding Solutions to Agency Problems

A performance bond is the prototype. Malfeasance is

discouraged by a potential penalty because the agent puts personal wealth in jeopardy, "up front," as the bond. If the norm of good behavior is maintained, the agent is paid opportunity costs plus interest on the bond. If malfeasance is detected, the bond is seized and the worker is fired. The potential unraveling problem at contract termination is solved by extending the worker's horizon and not returning the bond until after "retirement" as a pension (see Becker and Stigler [1974] for a very clear account). There exists a locus or trade-off of bond, detection-probability combinations that motivate the agent to adopt good behavior. Since resources used for monitoring have opportunity costs, it is economical to make the bond as large as possible and the probability of detection as small as possible [Becker (1968)] (ignoring type II errors).

Economists have used considerable imagination in applying this model. Lazear (1979) interpreted the bond-pension scheme very broadly. In his model workers are paid less than their value to the firm when young but more than their value when old. The negative difference between pay and 
value is a gradual posting of bond, with the worker effectively "investing" in the firm and becoming a "partner" for all practical purposes. This model implies a reduction in turnover. Studies of job turnover have established that after an experimentation period at the start of the life cycle, permanent attachments are made and turnover drops precipitously. Once a stable job has been found, it persists for remarkably long periods. Unfortunately, business executives have not been singled out for study, and there are serious gaps in the executive data for this purpose. However, a few conclusions may be warranted:

(i) Executives at or near the CEO rank in large corporations hold their positions for fairly long intervals and have been employed by the firm for a very long time. For example, in the samples used by Kostiuk (1989) and Murphy (1985), the average top level executive was 55-57 years old, had been in the position for seven or eight years, and had worked for the company for more than 25 years. In the larger Forbes sample of almost 1300 large corporations over 1974-1986, Jensen and Murphy (1990) report that CEOs who left office during that period had, on average, served for ten years. In the case studies discussed by Vancil (1987), 80 percent of "retired" CEOs remained on their firm's board of directors, and more than one-third served as Chairman of the Board. Barro and Barro (forthcoming) show a marked increase in departure probabilities of commercial bank CEOs after 63 years of age and associated with normal retirement. This is probably true of most industries.

(ii) There is more turnover below the very top ranking positions and in smaller firms. Nevertheless, Leonard's (1990) proprietary sample suggests that the matching process typically is completed by age 34 , the average age at which older executives were hired by their current employers 
in the sample. Casual evidence suggests substantial lower level executive turnover upon succession changes of top level management. A study by Lichtenberg and Siegel (1989) shows elimination of management/white-collar jobs when plants change ownership in leveraged buyouts. There is evidence that the same thing happens in unfriendly takeovers, mergers and acquisitions .

These observations are consistent with bonding and firm-specific capital accumulation among business executives, but knowledge of magnitudes is not available to assess their deterrence effects. The deterrence value of a bond depends on its size compared to the value of resources at risk of mismanagement and appropriation. Since a person's rank and responsibility in an organization grow over the life cycle, it is likely that implicit bonds are more efficacious for younger executives who have not yet gained control of much of the firm's resources. And since the value of large corporations exceeds the wealth of top managers by many orders of magnitude, bonds provide less scope for solving the agency problem at the top.

2. Loss of Reputation as Bond

Reputational considerations serve a bonding function in agency relationships, and though they lurk in the background of agency theory, formal analysis has proved elusive. An important exception is Fama (1980), who considered a model where observers use an agent's prior record and past history of performance to infer some personal trait, such as honesty. Knowing this, the agent has incentives to act in ways that affect the market's beliefs. The agency value of reputation arises because current behavior has an enduring "memory" when the legacy of the past is used to update current beliefs. Then current actions have long term consequences if the discount rate is not too large. Loss of reputation serves as a 
deterrent when the capital value of these consequences for earnings is greater than the bencfit of malfeasance, sloth and error in a current action.

Fama (1980) analyzed market equilibrium for a simple structure without discounting which converged to first-best efficient managerial behavior. Holmstrom (1982b) showed that discounting and risk aversion limit the extent to which reputation polices incentives. For example, finite life limits the extent to which the legacy of the past persists into the future (see Telser (1980) for the need for random horizons in self-enforcing agreements, and Radner (1985) on discounting in multi-agent problems). Reputation plays an ever smaller role in contract enforcement as the agent gets older because there is less to lose. At the end of the contract there is nothing to lose.

This horizon difficulty is reinforced by the fact that opportunities for misconduct increase as the successful agent's control over resources increases over the life cycle. One can be sympathetic, as I am, to the idea that there is much more to loss of reputation than merely financial opportunities -- social opprobrium, disapproval from one's peers, and loss of self-esteem have substantial deterrence value to many people, yet remain skeptical about their overall role in enforcing agency relations. Like performance bonds, reputation is likely to be more efficacious earlier rather than later in the life cycle.

3. The Stock Market and Corporate Control

As everyone knows, changes in ownership and control achieved new heights in the 1980s. The takeover phenomenon has much independent interest in the field of finance [see Jensen (1988)] and is beyond the scope of this review. However, a few findings have direct bearing on the subject 
at hand. Hostile takeovers and tender offers and attempts have attracted all of the research attention. Insofar as they represent a difference of opinion between current and potential new management on the efficient use of the firm's resources, they serve to check some abuses of current management in the use of those resources.

Successful hostile takeovers result in wholesale changes in management of the object firm. Evidence on reemployment opportunities of displaced top executives is scanty, but displaced executives probably do not find many doors open to them. It is also known that even unsuccessful takeovers serve to reallocate resources to the control of others through divestiture. Evidently the implied penalties to existing management from both successful and unsuccessful takeovers serve as some discipline for aligning current stockholder and managerial interests.

Nevertheless, other findings suggest that this discipline is incomplete. For instance, there is often substantial severance pay to top executives of object firms in mergers. The stock market views these "golden parachutes" as productive in converting what would otherwise be hostile reactions to friendly ones in takeover overtures (Lambert and Larcker (1985)], yet the implied behavior for those seeking such security seems curious. Second, object firms in takeovers tend to be in declining industries, where industry effects might be difficult to disentangle from firm-specific management effects (Morck, Shleifer and Vishny (1988), Lichtenberg and Siegel (1987)). Third, the takeover premium is about 40 percent (Jensen and Ruback (1983)). Thus it appears that existing managers can squander one-third of the firm's value before the threat of displacement becomes truly serious. Fourth, the market value of the average acquiring firm in a takeover shows little or no change. The market apparently puts 
small value in finder's fees and reorganization rents that might be expected from these activities. Perhaps competition among bidders accounts for this last finding, but it can't account for all of it if these activities are costly. It is not obvious why, when outsiders eliminate inefficient managers, practically all of the return should go to the shareholders of the mismanaged firms. Finally, Bhagat, Shleifer and Vishny (1990) find that 1980 s reorganizations "deconglomerized" many of the horizontal mergers assembled in the $1960 \mathrm{~s}$ and $70 \mathrm{~s}$. Hostile takeovers and attempts resulted in spinning off business lines to specialist firms and not to other conglomerates. A convincing theory of why these conglomerates were formed in the first place is not yet available.

\section{REWARDS TO ELICIT EFFICIENT ACTION}

All of the penalty modes constrain, but do not eliminate selfserving behavior. Hence there is scope for reward mechanisms to help align the interests of managers and shareholders.

A. Risk Sharing and Incentives

A fairly general approach was developed by Holmstrom [1979], who examined the following problem: Suppose an agent is hired by a principal to produce good $x$ with production function $x-f(l, \epsilon)$, where $\ell$ is effort and $\epsilon$ is a random variable with zero mean and known distribution. The agent is risk averse with concave utility $u=U(c, l)$, where $c$ is consumption. The principal is risk neutral. All production and utility functions are common knowledge and outcome $x$ is jointly observed by principal and agent. However, the action $\ell$ and the random variable $\epsilon$ are exclusive private information, either controlled or observed, of the agent. The principal has full property rights in $x$, which has unit price, and, for simplicity, 
supplies no inputs into the production process. The agent is paid a share $s(x)$ of the proceeds of $x$ because $\ell$ and $f$ are not separately observed by the principal: The goal is to characterize the equilibrium determination of $s(\mathbf{x})$.

The method of solution is interesting. It converts the market equilibrium problem into a two-stage maximum problem. The first step analyzes the agent's choice of $\ell$ that maximizes expected utility given $s(x)$. This yields a mapping from $s(x)$ to labor supply $\ell$. The second step solves for the function $s(x)$ that maximizes either the principal's expected profit or the expected utility of the agent, given the labor supply behavior in the first step. If profit is taken as maximand, another constraint is that the worker must expect to receive the known utility level of another job. If expected utility is taken as maximand, the added constraint is that the principal receives at least the expected return in some other activity. These alternatives give two extreme points on the utility-possibility frontier. Intermediate points are similarly obtained. Competition in the labor market insures that the equilibrium contract lies on the utilitypossibility frontier.

There is tension between efficlent action and efficient insurance in this problem. Were everything observable, the two could be unbundled. Then the risk-neutral principal would supply full insurance to the riskaverse agent by paying a fixed salary independent of outcome. The agent would willingly supply optimal effort (expected marginal product equals marginal cost) and monitoring would eliminate shirking. If the agent is risk neutral there are no gains from trade. The agent acquires ownership rights to $x$ and supplies optimal effort as a residual income recipient in self-employment. In all other cases, payment based on output alone through 
$s(x)$ gives only one instrument to perform two real allocative functions.

There aren't enough independent prices and margins to do either one sufficiently: The principal has to offer less than complete insurance to give the agent incentives to put forth effort.

It is remarkable that very little more can be said, in general, to characterize $s(x)$. Payments that are decreasing in $x$ through part of its range can't even be ruled out [Grossman and hart (1983)]! This negative result provides very few restrictions on data and makes the theory difficult to apply. What's worse, the contracts actually observed in agency relationships typically are of very simple forms which aren't predicted by this model.

The reason for these complications is difficult to describe. However, Holmstrom and Milgrom (1987) prove that $s(x)$ takes the simple linear form of a two-part tariff when income effects are absent in preferences and the technology shocks $\epsilon$ are i.i.d. An intertemporal version shows intuitively how it works. Consider an indefinitely repeated problem when $\epsilon$ is white noise and the action $\ell$ is chosen before $\epsilon$ is revealed in each round. With no income effects, the agent is content with the same amount of insurance each time irrespective of wealth, and similarly for the risk-neutral principal. Furthermore, i.i.d. production disturbances imply that each round looks exactly like every other from the production/incentive point of view. It is efficient for the agent to choose the same action in every period, because the agent's marginal rate of substitution between effort and consumption is independent of wealth and the expected marginal product of effort is constant. In the linear payoff schedule $s(x)=a+b x$ which implements the scheme, a serves as the insurance component and $\underline{b}$ as the incentive component [Stiglitz (1975)]. If $s(x)$ were nonlinear, the 
agent would have undesirable incentives not to take the same action each time; e.g.. to accumulate work into a large pile and do it all at once in a range where $s^{\prime}(x)$ is increasing.

B. The Optimal Piece Rate

Following Holmstrom and Milgrom (1989), consider the linear model for a risk averse agent with constant absolute risk aversion who produces two inputs, $x_{1}$ and $x_{2}$, for a risk neutral principal. Labor supplied by the agent is the only input. The agent receives a total payment $y$ consisting of a fixed lump sum and revenues from production of $x_{1}$ and $x_{2}$, each with separate piece-rates $b_{1}$ and $b_{2}$ :

$$
x_{i}=l_{i}+\epsilon_{i} \quad i=1,2
$$

$$
\begin{aligned}
& y=a+b_{1} x_{1}+b_{2} x_{2} \\
& u=u\left(y-c\left(l_{1}, l_{2}\right)\right)=-\exp \left(-R\left[y-c\left(l_{1}, l_{2}\right)\right]\right)
\end{aligned}
$$

where $R$ is the coefficient of risk aversion, $l_{i}$ is the effort devoted to activity $1, y$ is gross income, $c\left(l_{1}, l_{2}\right)$ is the agent's (convex) cost of effort and $\epsilon_{1}$ and $\epsilon_{2}$ are random variables with zero means and covariance matrix $\left(\sigma_{i j}\right)$.

Following the two-step procedure, take parameters $\left(a, b_{1}, b_{2}\right)$ as given and calculate the agent's labor supply to each activity: Substituting from (4), the agent chooses $\ell_{1}$ and $\ell_{2}$ to maximize

$$
E u-E U\left(a+b_{1} l_{1}+b_{2} l_{2}+b_{1} \epsilon_{1}+b_{2} \epsilon_{2}-c\left(l_{1}, l_{2}\right)\right)
$$


The first order condition is $\partial E u / \partial l_{i}=E U^{\prime} \cdot\left[b_{i}-\partial c / \partial l_{i}\right]-0$. Consequently,

$$
b_{i}=\partial c\left(l_{1}, l_{2}\right) / \partial l_{i}, \quad \text { for } i-1,2 \text {, }
$$

from which the labor supply functions $l_{i}-l_{i}\left(b_{1}, b_{2}\right)$ are obtained by inversion. Comparative statics on (6) yields the familiar

$$
\partial \ell_{i} / \partial b_{j}-(-1)^{i+j} c_{i j} / \Delta
$$

where $\Delta-c_{11} c_{22}-c_{12}{ }^{2}>0$. It follows that $\partial l_{i} / \partial b_{i}>0$ : an increase in the payment for an output increases the effort devoted to it. Also, $\partial l_{i} / \partial b_{j}<0$ for $i \neq j$ when $c_{i j}>0$ : an increase in the price of one good decreases the effort supplied to the other.

In the second step, the risk neutral principal has profit $-p_{1} x_{1}+p_{2} x_{2}-a-b_{1} x_{1}-b_{2} x_{2}$, where $p_{1}$ is the relative (market) price of $x_{1}$. Consider the case where the expected return to the principal is driven to zero. Then $\left(a, b_{1}, b_{2}\right)$ is constrained by

$$
E_{\pi}=0-\left(p_{1}-b_{1}\right) l_{1}+\left(p_{2}-b_{2}\right) l_{2}-a .
$$

The market equilibrium contract $\left(a, b_{1}, b_{2}\right)$ is the one that maximizes the agent's expected utility Eu, subject to the labor supply functions derived in the first step and to (8).

Substituting (8) into Eu

$$
E u-E U\left(p_{1} \ell_{1}+p_{2} \ell_{2}+b_{1} \epsilon_{1}+b_{2} \epsilon_{2}-c\left(\ell_{1}, \ell_{2}\right)\right)
$$


where $\ell_{i}-l_{i}\left(b_{1}, b_{2}\right)$ satisfying (6) is understood. Differentiating (9) with respect to $b_{i}$ and simplifying gives, for $1=1,2$

$$
\partial E u / \partial b_{i}-\left[\left(p_{1}-c_{1}\right) \partial l_{1} / \partial b_{i}+\left(p_{2}-c_{2}\right) \partial l_{2} / \partial b_{i}\right] E U^{\prime}+E U^{\prime} \epsilon_{i}=0
$$

where $\partial \ell_{i} / \partial b_{j}$ satisfies (7). Finally, substituting the CARA utility function into (10)

$$
\left(P_{1}-c_{1}\right) \partial l_{1} / \partial b_{i}+\left(P_{2}-c_{2}\right) \partial l_{2} / \partial b_{1}-R\left(b_{1} \sigma_{11}+b_{12} \sigma_{i 2}\right)=0, \quad i=1,2 .
$$

gives two equations in two unknowns to solve for $b_{1}$ and $b_{2}$.

Equation (11) illustrates the balancing between incentives and insurance in the optimal contract. The marginal costs of effort, $c_{1}$ and $c_{2}$, would equal their marginal rewards, $p_{1}$ and $p_{2}$, in a first best solution. In (11) there is a wedge between the marginal cost and marginal benefit of efforts in each good. These are weighted by the marginal response of effort to its internal price to arrive at an average deviation and balanced against risk considerations in the last term of (11). Relevant risk in the contract is an average of the variances of each output weighted by internal prices and the extent of risk aversion. Departures from first-best incentives increase with risk and the agent's sensitivity to it.

A little more progress can be made by manipulating (11) to

$$
b_{i}-\left[R \sigma_{j j}\left(c_{j j}-p c_{i j}\right)-R \sigma_{i j}\left(p c_{i i}-c_{i j}\right)+1\right] \Delta / D
$$

where $D-\left(R \sigma_{11} \Delta+c_{22}\right)\left(R \sigma_{22} \Delta+c_{11}\right)-\left(R \sigma_{12} \Delta+c_{12}\right)^{2}$. Even this is unwieldy, but two special cases suffice for present purposes. 
(i) Let $c_{12}-\sigma_{12}-0$. Then the two activities are independent of each other and (12) reads as

$$
b_{i}^{*}-p_{i} /\left(R \sigma_{i i} c_{i i}+1\right) \quad i-1,2
$$

Piece rates vary inversely with risk aversion, $R$, the size of the risk, $\sigma_{i i}$, and the relative responsiveness of labor supply to price, $c_{i i}$, and vary positively with the market value of output produced, $p_{i}$.

(ii). Let $c_{12}>0$ and $\sigma_{12}=0$. Now the activities compete with each other because doing more of one increases the marginal cost of the other. Substituting into (12), one eventually arrives at

$$
b_{i}-b_{i}^{*} \text { plus a term in }\left[R \sigma_{11}\left(c_{12}-c_{i 1}\right)-1\right] \text {. }
$$

where $b^{\star}$ is defined in (13). The second term in this expression is negative so long as $c_{i i}>c_{12}$, that is, if, from (7), the own responsiveness of effort to price is no smaller than the cross responsiveness. Then $b_{i}$ is smaller than $b_{i}{ }^{\star}$. Piece rates are smaller when activities compete with each other in the agent's effort. There are negative externalities between the two activities when $c_{12}$ is positive. These are effectively "taxed" by reducing the marginal incentive components in the contract, so substitution between activities gives rise to relatively insensitive internal incentives, to "low powered" incentives in the sense of Williamson (1985).

\section{B. Some Qualifications}

Another, perhaps more fundamental reason why the optimal contract might back off from sensitive performance incentives is that output and performance of managers often are hard to measure. The services rendered by 
business managers in large firms cannot be assessed on a fixed scale of attributes. If the list of variables is incomplete, then scoring performance on such a scale might exaggerate the production of those attributes that are only imperfectly correlated with the true value of the service. Important intangibles would not be rewarded sufficiently. Though the point is an old one, it has been applied only recently to labor market incentives. Baker (1989) shows that imperfect correlation between the assessment of performance and true output acts like a reduction in $p_{i}$ in the formula for $b^{\star}$ above. It reduces the weight of marginal incentives in determining executive pay, and by implication, increases the weight of fixed salary.

Such considerations are more appropriate for lower level managers than for those close to the top of the ladder. Contributions of lower level managers to the success of an organization are difficult to isolate, submerged, as they are, in the joint output of the team as a whole. Lifecycle considerations also play an important role there (see below). Incentives can't be so diluted for high-ranking people, who take ultimate responsibility for the success of the organization as a whole. If they are rewarded on market valuation and profitability of the firm, there is no need to assess and price out each of the many activities that contribute to it. There is no need to reduce the "power" of incentives to them (Lazear (1986)].

An important qualification remains. Rewards that promote good incentives must be indexed to outcomes that managers can alter. Stock market values and current profits are only partly affected by managerial decisions. They also are affected by business conditions beyond any manager's control. Lazear and Rosen (1981) pointed out that relative 
comparisons wash out common components of variance among competitors and isolate specific performance-related components. The idea is analyzed most completely by Holmstrom (1982a), who showed that relative comparisons eliminate a source of extraneous risk for agents. Increasing the signal-tonoise ratio makes managerial incentives more effective and contracts more efficient.

\section{The Evidence}

Top executive compensation in a large firm is set by the Board of Directors, often with the assistance of management consultants [Tosi and Gomez-Mejia (1989)]. The contracts themselves are not public information, but there is little doubt that remuneration is tied to the fortunes of the firm. There are, however, differences of opinion about how performance is measured for compensation purposes and about the magnitude of the effects. The earliest studies on the sales-profits debate summarized above generally found larger effect of sales than of profits (Roberts (1956), McGuire, et al. (1962)]. Later studies [Lewellen and Huntsman (1970), Kokkelenberg (1988), Winn and Shoenhair (1988)] tended to find stronger effects of accounting profits on compensation, but at least an equal number have found evidence for both (Meeks and Whittington (1975), Kostiuk (1986, 1989), Ciscel and Carroll (1980), Leonard (1990)], with the picture slightly clouded by multicollinearity. Since size must be an important correlate of pay if more talented persons control greater resources, posing the agency question in terms of sales versus profits is not meaningful in the available data. The managerial hypothesis that size is larger than it otherwise would be is a counterfactual that cannot be answered at the moment. Looking at all the studies together I cannot see clear winners in the earlier debate. Both performance and scale are important. I confine attention to those 
studies where elasticities are presented or can be computed. All of the estimates refer either to the CEO or to the top five executives. Some use salary and bonus as independent variable, others a more comprehensive definition that includes deferred compensation and options.

Kostiuk (1986) estimates a semi-elasticity of the accounting rate of return on compensation (defined as $d \log$ (compensation)/dr, where $r$ is the rate of return) of about 1.25 for the United States in both the 1930 s and early 1970s. This compares quite well with Cosh's (1975) estimate of 1.0 for Britain in the early 1970s. In recent years, empirical studies have tended to use the stock market rate of return as the performance measure rather than accounting rates of return. This reduces the elasticity estimate by almost a factor of 10 .

Murphy (1985) estimates a semi-elasticity of compensation with respect to the rate of return to shareholders of .12 to .16 using a 73 firm sample of firms during 1969-81. Murphy (1986) produces a similar estimate on a much larger Forbes sample of about 250 large firms over 1974-84. Earlier, Masson (1971) estimated statistically significant effects of stock returns on CEO compensation from a 39-firm sample over 1947-66, though the coefficients themselves are not reported. Coughlin and Schmidt (1985) estimated a semi-elasticity of .10 to .15 on a 40 -firm sample from Forbes during 1978-80. The study is notable for using the abnormal stock return (estimated from CAPM) instead of the raw return. Murphy (1985) tried both abnormal and total returns in a within-firm compensation regression. Most of the estimated effect goes to the raw return, and it doesn't seem to matter which one is used, so long as both aren't used together. Again, there is evidence that this estimate is remarkably uniform from study to 
study, e.g., consider that Barro and Barro (forthcoming) report an estimate of .17 for bank CEOs over 1982-87.

Coughlin and Schmidt (1985) were among the first to use a relative performance measure, yet Murphy's (1985) empirical competition between relative and absolute stock returns suggested that relative performance didn't matter. Relative performance evaluation was principally addressed by Antle and Smith (1986) using Masson's 1947-66 sample. They found only weak evidence to support the idea. It was definitely rejected for 15 out of 37 firms studied, while wrong signs on the systematic and firm-specific components were obtained for many others. Barro and Barro (forthcoming) find no evidence of relative performance evaluation among bank CEOs, even though there were marked differences in fortunes among regional economies and their constituent banks during the period of analysis.

A recent study by Gibbons and Murphy (1990) uses the largest (Forbes) sample and provides the most evidence supporting relative performance evaluation. They include the average rate of return on stock in the firm's industry and the firm's own rate of return in the compensation regression, rather than abnormal performance, CAPM-measures. They find positive effects of own return on executive compensation and negative effects of industry average return. While it is the strongest evidence for relative performance effects yet found, anomolies remain because industry effects are larger at the most aggregate level than at the firm's own fourdigit level. The estimated effect may be sensitive to how relative performance is measured. Hence the overall picture on relative performance effects is somewhat more on the negative than positive side of the ledger.

Most studies so far have examined whether pay and performance have positive partial correlation. This is the natural first approximation, but 
there are only a few more ambitious studies that purport to examine causation. This program was begun by Masson (1971), who investigated how various components of pay affect firm performance. The method used is flawed and has not been pursued. Leonard (1990) regressed the rate of return on equity on various aspects of pay and incentives for executives within ten levels of the top in a proprietary sample. No clear general picture emerges because the effects differ in sign when estimated within and between firms. Abowd's (1990) study on these proprietary data is notable for asking whether changes in the sensitivity of pay to ferformance affects subsequent performance. Evidence of such effects is found for stock market performance indicators, but not for accounting measures. The inventory of studies is too small to make definitive judgements on causality right now. Hopefully more studies along these lines will be forthcoming.

Finally, some studies have examined the sensitivity of pay components to performance. Most studies above conclude that current performance rewards come about through adjustment of the bonus and components of compensation other than salary. Salary is a substantial part of compensation, but acts more like the fixed term $\underline{a}$ in the development above. One thinks that salary adjustments should respond to longer term components of performance and bonus to shorter term components, but this is an understudied point. Eaton and Rosen (1983) consider the difference between long- and short-term incentives by examining the correlates of current and deferred pay components. However, Miller and Scholes (1982) argue convincingly that these forms of compensation are tied up with tax laws so it is difficult to distinguish the two. For instance, stock options were not used for compensation until the early 1950s, when upper bracket marginal tax rates were very high. Morck, Shleifer and Vishny (1988a) find 
a curious nonmonotonic relationship between management stock ownership and firm performance. Using a cross section of large U.S.firms in the 1980 s, they find that performance measured by Tobin-Grunfeld's $Q$ increases with stock ownership of Board members (including the CEO) when it is less than 5 percent of total stock, decreases with ownership in the 5 to 25 percent range, and perhaps increases again above that range. No compelling explanations have appeared as yet for this unusual finding.

\section{Assessment}

Though there is little doubt that top executive's incomes vary with the fortunes of their firms, the picture is mixed relative to theory. Confirming evidence from several independent studies and samples leaves us fairly secure that the effect of stock returns on $\log$ compensation is in the $0.10-0.15$ range. The many estimates of accounting rates of return on compensation don't lend themselves to such ready comparisons, even though most studies do find positive effects. The best available comparable estimates are in the range $1.0-1.2$, and quite a bit larger than for rates of return to stock ownership.

I cannot express a clear preference between these two alternatives. Many economists simply dismiss accounting profits as too easily manipulatable by top managers to be suitable contractual measures of performance. Such dismissal is simply wrong. Not only is it known that explicit provisions of executive contracts are in fact tied to accounting numbers, but the deeper intellectual question is whether market or accounting returns are more informative for executive incentives [Lambert and Larker (1987)]. It cannot be true that accounting information is worthless in the giant firms in question, since they simply couldn't exist without it. Finally, accounting numbers are the main source of information 
not only for managerial decisions. They also inform the stock market. Top executives are in a repeated game, constantly observed by bird-dogs, market makers and, even worse, raiders. This limits possible misrepresentation for compensation purposes. For sure, depreciation methods and special charges can be chosen advantageously on occasion. Yet these manipulations can't occur very often and have future costs as well as current benefits. . Undoubtedly, stock values are less easy to manipulate in this sense, but how much information about performance do they contain? The stock price of a firm changes for many reasons that are independent of its performance. Some underlying causes such as shifts in industry demand have similar effects on accounting profits. Others, such as changes in the market discount rate, are specific to the stock market alone. There are parallel sources of independent noise for accounting measures. Putting them side by side, which measure has the greater signal power for managerial performance? Strong findings on relative performance evaluation would have shed light on this, but only one study has found evidence for it. Bonus and other payment mechanisms are seldom explicitly triggered by stock performance in executive contracts. Options and deferred stock appreciation rights are exceptions, but their value depends as much on the general state of the stock market, which managers cannot affect, as on firm-specific performance.

Jensen and Murphy (1990) argue that the empirical relationship between pay and performance, while positive, is too small to provide adequate incentives for managers to act in shareholders' interests. Using the Forbes 1974-86 sample, they regress the arithmetic first difference in annual CEO compensation (including the change in personal wealth tied up in the firm) on current and lagged arithmetic changes in shareholder wealth and 
a few other variables. An attempt is made to eliminate the effects of market noise by using relative performance indicators, though they are unsuccessful here.

An estimate for $d \log$ (compensation)/dr of .1 estimated in earlier studies seems "reasonable," so it comes as a considerable surprise that the estimated values in the arithmetic regression for $d$ (compensation)/dr are extremely small. The differences are due to the fact that the ratio of CEO compensation to shareholder wealth is vanishingly small in these giant corporations (on the order of $6 \times 10^{-4}$ at the median and $10^{-3}$ at the mean). In the simplest specification, the first difference regression implies that annual salary and bonus increase by a mere $\$ 13.50-\$ 21.00$ when shareholder wealth changes by $\$ 1 M$. Adding the effects of own stock holdings, options and the like increases the estimates to $\$ 32.50$. Since mean compensation is more than $\$ .5 M$ per annum and personal wealth is much larger than that, these are very small sums indeed, small enough to raise questions about the role for compensation mechanisms to align the interests of managers and owners.

Still, Jensen and Murphy's (1990) estimates are substantially smaller than those implied by other studies. Considering that both dividends and the number of shares of stock outstanding hardly changes in a short time series, the rate of return on stock ownership, $r$, is approximately equal to the percentage change in total market shareholder value. Let $\Delta V$ represent the arithmetic first difference of total shareholder value and $\Delta y$ the arithmetic first difference in salary and bonus. Jensen and Murphy estimate $\tilde{b}_{1}-\Delta y / \Delta V=1.35 \times 10^{-5}$. The semielasticity estimate discussed above is $\tilde{b}_{2}-\Delta \log y / \Delta r-(\Delta y / y) / \Delta r$ for which .1 serves as lower bound. Now, since $\Delta r=\Delta V / V$, it follows that $\bar{b}_{2} \approx \bar{b}_{1} \cdot V / y$ and $\tilde{b}_{1} \approx \bar{b}_{2} y / v$, where $y$ and $V$ are evaluated near the mean of 
the sample. Since $y / v=10^{-3}$ at the mean, the implied estimate of $\tilde{b}_{1}$, when $\tilde{b}_{2}=1$, is $10^{-4}$ - or almost eight times larger than their estimate of $1.35 \times 10^{-5}$. This implies a total effect of at least $\$ 100$ salary and bonus change per $\$ 1 M$ change in shareholder value, compared to their estimate of $\$ 13.5-\$ 20.00$. Working their estimate the other way round leads to an implied elasticity near .014 and much smaller than the direct estimate of .1 found by others in these data.

Functional forms must account for these differences. Most empirical economists would argue for using log rather than arithmetic differences because the latter are dominated by large firms. Furthermore, the arithmetic effect is expected to decrease for large firms (as Jensen and Murphy confirm) because the risks are larger. Since the rate of return is largely independent of size, the directly estimated elasticity form $\left(\bar{b}_{2}\right)$ better controls statistically for size effects.

Going out on a limb, the $10^{-4}$ estimate of $\bar{b}_{1}$ implied by the $\log$ version suggests that CEO's lose $\$ 100,000$ in direct pay per $\$ 1 B$ decline in stock value. Now a $\$ 1 B$ change is large - about 20 percent of the average firm's value in the sample. However, the $\$ 100,000$ is in the range of 20 percent of average compensation. Considering that CEO personal asset holdings are almost surely less diversified than the average stockholder [Lewellen (1968), Deckop (1988)], CEOs risk a considerable portion of their personal wealth from the actions they take on behalf of shareholders. What isn't so clear from theory is what a reasonable benchmark would be. Is the .1-.15 elasticity estimate too small or too large? The theory hasn't focused enough on that number to provide an answer. 


\section{CAREER INCENTIVES}

Much of the literature has analyzed incentives in a timeless context. Interactions between the selection and incentive problems give rise to important new issues when the problem is examined over a person's career. Resources must be reassigned among managers over time, as older generations retire and are replaced by younger generations. Aspiring executives start their careers in low level positions and work their way up through the ladder to higher level positions over the life cycle. How a career develops depends on the quality of the person's previous work, what talents were demonstrated in lower positions, and the talent of other people who are available to be selected. Selection and incentives are intertwined by competition for promotion to higher-paying positions and by attempts to affect the selection process.

\section{A. Nature of the Problem}

Again, the manager's horizon is crucial to this problem. Career considerations are more important at the beginning of a career than at the end. Toward the end of a career, if not before, the cards have been dealt and one's hand is pretty much known. Higher level reassignments are unlikely, or impossible. At that point the potential influence of future prospects vanishes and only current incentives matter. Analyzing the very top level executive labor market with a timeless context is a good approximation for this reason. However, learning, incentives and aspects of competition for positions necessarily arise when examining the market as a whole.

A promising approach is taken by Gibbons and Murphy (1990b), who extend the linear piece rate model to many periods. The model is specialized to only one activity but is generalized to include two sources 
of noise. Uncertainty about the agent's ability is added to the pure randomess and/or measurement error in the mapping from effort to output in early periods.

The problem is solved by backward recursion. Consider two periods. The solution in the last period follows that outlined above, with the proviso that it is conditioned on whatever is known about the person's ability at the end of the previous period. Information has no value in the final period and there is no investment in it by either principal or agent. Information acquired in the first period does have value because it can be exploited later. Given anticipated optimal behavior in the second period, investments. in information give extra first-period work incentives over and above the piece rate. Specifically, the agent has incentives to increase the signal-to-noise ratio in output to enable better assessment of ability. Raising the first period piece rate isn't so necessary for incentives because learning and piece rates are substitutes for each other. Such substitution actually occurs in Gibbons and Murphy (1990b) for risk reducing reasons, and the piece-rate price $b$ is actually smaller in the first period than in the second.

Earifer, Murphy (1986) had contrasted pure learning with pure incentive theories of the executive labor market. In the learning theory the manager is paid the value of expected productivity estimated from previous output. Bayesian inference implies that more is learned at the beginning of a career than at the end because additional samples hardly affect the posterior distribution when the number of observations is already large. On the other hand, the atemporal incentive problem looks much the same from one period to the next. Thus the learning model would imply less sensitivity of compensation to output for more experienced executives while 
the pure incentive model would not. When the two forces are combined, incentives to invest in learning still decline over time and less learning takes place, but now it is necessary to substitute current performance incentives for diminishing career incentives over the life-cycle. This implies that sensitivity of pay to current performance should actually increase for more experienced executives whose horizon is shorter than the less experienced.

\section{B. Promotions and Career Incentives}

Career considerations loom large in promotion of executives across ranks in the corporate structure. Evidence exists that much human capital investment is related to these kinds of job changes [Sicherman and Galor (1990)] in the labor market generally. Still, there are reasons to suspect that these aspects of work are much more important for executives than for other workers. Advancement in rank in the officer corps of a military organization is a useful rigid hierarchy version of the process to keep in mind (though the up-or-out feature usually isn't encountered in firms). Large firms, such as oil companies with far flung foreign operations, rotate high level personnel through the system and through the ranks much like the military. No doubt differences in style and technology make it a poorer approximation for many firms, yet essential elements remain common to all of them.

Promotions focus an executive's career attention on those discrete points when a "window of opportunity" opens for possible advancement. Typically these windows fit some predetermined rough outline of the firm's organization structure and there is competition for them from contenders, both within and without the firm. This process can be modeled as a tournament (see Lazear and Rosen (1981) for an early analysis). Competitors 
with the highest scores on some performance criteria are declared winners and get promoted to a better job. Comparison methods in statistical experiments come to mind as a possible model, with the crucial difference that the objects of the experiment can and do take actions to influence the outcome. Where one gets classified in this competition makes an enormous economic difference to a person.

It is interesting that within-firm competition sometimes can be structured to approximate socially optimum incentives by adjusting the wage structure across job ranks. The idea is simple. Incentives to put forth effort to win are increasing in the difference in prizes between winning and losing. Sirce incentives vanish when the difference in compensation vanishes and increase without bound in the other direction, there exists a between-rank wage structure that promotes the optimal amount of effort (in the sense that the expected marginal product to the firm of such effort equals its marginal $\cos t$ ). Much has been made of setting the scope and limitations of this result. Levinthal (1984), McLaughlin (1988), and Mookerjee (1989) provide excellent surveys to which the reader is referred for details. Instead of providing another review, I use the idea to illustrate some effects of career considerations on the organizational wage structure.

Think of a career as stochastically climbing a ladder. Ultimately the person comes to rest at some rung, perhaps at the top but usually before. This scheme loosely follows a sequential design-of-experiments, where "losers" are successively culled from the sample and not allowed to continue. It economizes sample size and gains information efficiently. Incentive issues arise from the stopping rule. A person's horizon in this game falls to zero when being passed over for promotion enough times 
eliminates opportunities to continue. From that point on current monetary incentives and monitoring must motivate job performance. However, those who are still "alive" and contending in the promotion game have a longer horizon which weighs into their decision to put out efforts to climb higher. Simple formulations of this problem have been analyzed [Rosen (1986)]. The value of winning at any stage is not only the winner's prize (compensation) at that level, but also includes the value of an option to compete for larger prizes at higher levels. The value of this option reflects career considerations .

The value $v_{t}$ of contending in $a$ game in which there are $t$ stages remaining is

$$
v_{t}=\max \left\{P(\ell, \bar{l}) v_{t-1}+\{1-P(\ell, \bar{l})] W_{t+1}-c(l)\right\}
$$

where $P(\ell, \bar{l})$ is the probability of winning when own effort $\ell$ is expended and efforts $\bar{l}$ are expended by other competitors, $W_{t+1}$ is the compensation paid to the loser and $c(l)$ is the (convex) cost of effort. The first order condition for this problem is

$$
\left(v_{t-1}-w_{t+1}\right) \partial P / \partial \ell-c^{\prime}(l)
$$

Defining $\mu-(\partial \log P / \partial \log \beta) /(\partial \log c / \partial \log \ell)$, manipulating (15) into an elasticity form and substituting out for $c$ in (14) yields a recursion for $v_{t}$

$$
v_{t}-\beta_{t} v_{t-1}+\left(1-\beta_{t}\right) w_{t}
$$


where $\beta_{t}-P_{t}\left(1-\mu_{t}\right)$ is evaluated at the Nash equilibrium effort levels and probabilities. Assuming $0<\beta_{t}<1$ and using the boundary condition that $v_{0}-w_{1}$, where $w_{1}$ is the highest ranking prize (the CEO's compensation), the solution to (16) is

$$
v_{t}-\left(\beta_{1} \beta_{2} \ldots \beta_{t}\right) \delta w_{1}+\left(\beta_{2} \ldots \beta_{t}\right) \delta w_{2}+\ldots+\beta_{t} \delta w_{t}+w_{t+1}
$$

where $\delta W_{i}-W_{i}-W_{i-1}$ is the difference in prizes between adjacent ranks. The option value $v_{t}$ in (17) is the sure prize $w_{t+1}$ if the contest is lost plus the discounted sum of differences in rewards between ranks in future rounds. The discount factor $\beta_{t}$ depends on the probability of winning and the costs and technology of doing so. Subtracting $w_{t+2}$ from both sides of (17) and comparing it with (15) shows that the incentives to win are increasing in the option value, specifically,

$$
\left(v_{t-1}-w_{t+1}\right)-\left(\beta_{1} \ldots \beta_{t-1}\right) \delta w_{1}+\left(\beta_{2} \ldots \beta_{t-1}\right) \delta w_{2}+\ldots+\Delta w_{t} .
$$

The firm desires that effort expended by people in higher positions be at least as large as that expended at lower levels, if the multiplicative effects in section II exist. This is why executives work such long hours. In a pure incentive game where the contenders are known to be of similar talent, $\beta$ works out to be a constant independent of $t$ and and it can be shown that compensation differences between adjacent ranks below the top are necessary to induce nondecreasing effort across ranks. However, the option to continue plays out at the final round, so the difference in compensation between the $C E O$ and first Vice President must be increased to make up for it. There is an extra prize at the top. 
The economics is that this increment acts to extend the effective horizon, "as 1f" the promotion ladder were of infinite length and competitors were in a game which continued forever. The idea survives many generalizations. It suggests that the wage structure in a hierarchical organization should exhibit a certain "convexity:" whereby CEO compensation is out of step and elevated above the rest for motivational purposes in the organization as a whole. More generally, when managers compete to change their positions over their careers, wages at any given level have spillover effects on the incentives of contenders at lower levels.

Competition generated by these kinds of relative performance evaluation can lead to moral hazard problems. Competitors may collude (Dye (1984)] and put forth less effort than is appropriate, to the detriment of the organization as a whole. Alternativly, there may be opportunities for destructive activities of competitors to denigrate the work of others and make one's self look better by comparison [Lazear (1989)). Such antisocial behavior can be partially controlled by reducing the stakes and narrowing wage differentials between ranks, but it comes at the cost of reducing effort in the organization as a whole. It might also be controlled by recruiting personnel for these positions from outside the organization. An alternative view has been little studied: Breton and wintrobe (1986) describe a form of competition within a patronage system. The CEO encouraged competition among his immediate subordinates, who in turn served as patrons for those lower down the hierarchy. Those further below knew the game and took actions to improve the standing of their patron in the eyes of the CEO because that could improve the subordinate's standing. The scheme has qualities of an "Invisible hand," though used to totally corrupt purposes in their case study. 
These moral hazards are not specific to tournament structures. Rather they apply to any incomplete scoring scheme for assessing talent. Tirole (1986) analyzes collusion between an agent and supervisor, both against the principal. Milgrom (1988) considers the effects of socially unproductive activities taken by an agent to influence the scoring system. Both considerations appear to generate incentives for more rigid and bureaucratic rules within an organization relative to using internal prices to self-regulate behavior.

C. Evidence

Data Iimitations on executive careers and incomes below the top have limited empirical work in this area. Some of the implications of these models have been borne out in experiments and a few have not [Bull, et al., (1987,1988)], but there is less evidence from the market itself. Rosenbaum (1984) documented career paths through promotion in a case study of one large firm. Proxy statements of large firms often list total compensation of the highest paid twenty or thirty executives and suggest that top executives are indeed paid substantially more than those immediately below them. This is confirmed in Leonard's (1990) proprietary sample, where differences in pay increase markedly between adjacent levels in moving from bottom to top. He also reports that pay increments are negatively correlated with promotion prospects, consistent with requirements for incentive maintenance when competition is stiffer. Yet, in a single year cross-firm comparison, O'Reilly et al. (1988) found that pay differences between CEO and vice presidents were negatively correlated with the number of vice presidents. A positive correlation is expected if more vice presidents are contending for the CEO position. Perhaps some of them aren't competing. The convexity implication within firms is also found by Lambert, 
et al. (1989) in a large proprietary sample. Differences in pay between levels increase rapidly with rank in their sample, and the CEO earns on the order of $\$ 100,000$ more, compared to $\$ 10,000 \cdot \$ 30,000$ median differences at lower levels.

There is evidence supporting direct substitution of current for career incentives of CEO's as time to retirement decreases. Gibbons and Murphy (1990b) examine Forbes' sample CEOs who left their firms over 1974. 89. The elasticity of pay to stock market value is the usual. 10 when these people had many years remaining, but rises to .18 when they had few years left. Previously. Murphy (1986) found that the relation between CEO pay and stock market rate of return was larger in earlier years of CEO tenure in both position and in the firm, and Barro and Barro (forthcoming) found declining sensitivity of pay to performance with age of CEO. However, neither studies time-remaining nor controls for CEO stock holdings, which tend to grow withtenure. Own stock holding in the firm gives immediate performance incentives and reduces the need for sensitivity in direct compensation.

Avallable evidence generally supports some of the life cycle and other implications of these models. However, more evidence is needed.

VI. CONCLUSIONS

This survey demonstrates great scope for fruitful empirical and theoretical research in this area. As usual, much remains to be done.

On the empirical side, inquiry must dig deeper into the management hierarchy. In some ways our preoccupation with top executives is examining the tip of the iceberg. However, much effort at data development will be necessary for such endeavors. Empirical investigation also must be 
broadened beyond the U.S. to other countries. How will these remarkably uniform estimates compare around the world? It is commonly alleged, for example, that Japanese business executives earn much less relative to production workers compared to their American and British counterparts. It would be very interesting to know if the compensation elasticities of .25 for scale and .10 for shareholder wealth nevertheless hold true in Japanese firms. In addition, executive ranks recently have opened up to women in many countries. The marked increase in available supplies of managerial talent should have large consequences on the executive labor market, which remain to be worked out and examined empirically.

of the many theoretical issues on the research agenda, a few stand out. First, many alternative mechanisms for affecting managerial incentives have been identified. How should the effects of reputation, bonding, takeovers and compensation contracts be parceled out? To what extent do these alternatives act as substitutes for each other, or as complements? Second, perhaps the idea that shareholders are the only principals in the executive contracting problem is too simple. There is much to be said for the view of a firm as a "nexus of contracts." Then control decisions affect the wealth of many contract holders in the firm. For example, shouldn't debt holders [Fama and Jensen (1983)] be included as claimants of the firm's resources and included in the empirical estimates of wealth elasticities? Furthermore, what limits the scope of control? Labor economists have increasingly recognized the importance of firm specific human capital; and firm-specific capital is often involved in contracts with specialty suppliers and other intermediaries. All of them have a stake in how the firm is managed. Evidence on this broadened "stakeholder" view of claimants is hardly to be found, and though it is not compelling for the case of 
hostile takeovers [Shleifer and Summers (1988), Kaplan (1989)), these issues are likely to be more generally important. They deserve more attention.

Einally little has been done on executive succession and how incompetent executives are rooted out, short of the draconian takeover solution. Vancil's (1987) interesting account of how CEO's are chosen is necessarlly limited by the small selection of firms in its case study approach. Any executive selection process is subject to error, but little if anything is known about how mistakes are corrected. If, as I maintain, competence has extraordinary marginal product for top management positions in large firms, how incompetence is revealed and handled must be important Formally, the job falls to the Board of Directors. Yet there is much opinion and some evidence (e.g., board compositions change when the CEO changes [Hermalin and Welsback (1988)]) that Boards are themselves controlled by the CEO. The implied limits on monitoring would appear to make the contractual approach more important. 


\section{REFERENCES}

Abowd, John, "Does Performance Based Management Compensation Affect Corporate Performance?" Industrial and Labor Relations Review 43 ( 3 , 1990): $52 s-73 s$.

Antle, Rick, and Abbie Smith, "An Empirical Investigation of the Relative Performance Evaluation of Corporate Executives, "Journal of Accounting Research $24(2,1986): 1-32$.

Baker, George P., "Piece Rate Contracts and Performance Measurement Error," Harvard Business School, 1989.

Berro, Jason R., and Robert J. Barro, "Pay, Performance and Turnover of Bank CEOs," Journal of Labor Economics (forthcoming).

Baumol, William J., Business Behavior, Value and Growth, Revised edition (New York: Harcourt Brace), 1967.

Becker, Gary S., "Crime and Punishment: An Economic Approach," Journal of Political Economy $76(2,1968): 169-217$.

Becker, Gary S., and George J. Stigler, "Law Enforcement, Malfeasance, and Compensation of Enforcers," Journal of Legal Studies 3 (1, 1974): $1-18$. Bhagat, Sanjai; Andrei Shliefer and Robert W. Vishney, "Hostile Takeovers in the 1980s: The Return to Corporate Specialization, "University of Chicago, 1990.

Breton, Albert, and Ronald Wintrobe, "The Bureaucracy of Murder Revisited," Journal of Political Economy $94(6,1986): 905-926$.

Bull, Clive; Andrew Schotter, and Keith Weigelt, "Tournaments and Piece Rates: an Experimental Study," Journal of Political Economy 95 ( 1 , 1987): $1-33$. 
"Assymetric Tournaments, Equal Opportunity Laws and Affirmative Action: Some Experimental Results, "Wharton School, University of Pennsylvania, 1988.

Ciscel, David H., and Thomas M. Carroll, "The Determinants of Executive Salaries: An Econometric Survey," The Review of Economics and

Statistics $62(1,1980): 7 \cdot 13$.

Cosh, Andrew, "The Remuneration of Chief Executives in the United Kingdom," Economic Journal $85(1,1975): 75-94$.

Coughlin, Anne I., and Ronald Schmidt, "Executive Compensation, Management Turnover, and Firm Performance: An Empirical Investigation, "Journal of Accounting and Economics 7 (2, 1985): 43-66.

Deckop. 'John R., "Determinants of Chief Executive Officer Compensation," Industrial and Labor Relations Review 41 (2, 1988): 215-226.

Dunlevy, James A., "Econometric Issues in the Analysis of Executive Compensation," Review of Economics and Statistics 67 (1, 1985): 171 . 174.

Dye, Ronald, "The Trouble with Tournaments, "Economic Inquiry 22 (1, 1984): $147 \cdot 149$

Eaton, Jonathan, and Harvey S. Rosen, "Agency, Delayed Compensation and the Structure of Remuneration," Journal of Finance 38 (5, 1983): 1489-1505.

Fama, Eugene, "Agency Problems and the Theory of the Firm," Journal of Political Economy 88 (2, 1980): $288-307$.

Fama, Eugene F., and Michael C. Jensen, "Separation of Ownership and Control," Journal of Law and Economics 26 (2, 1983): $301-325$.

Gibbons, Robert, and Kevin J. Murphy, "Relative Performance Evaluation for Chief Executive Officers," Industrial and Labor Relations Review 43 (3, 1990a): $30 s-51 s$. 
, "Optimum Incentive Contracts in the Presence of Career Concerns,"

University of Rochester, $1990 \mathrm{~b}$.

Grossman, Sanford, and Oliver Hart, "An Analysis of the Principal-Agent Problem," Econometrica 7(1, 1983):

Hermelin, Benjamin, and Michael Weisback, "The Determinants of Board Composition" Rand Journal of Economics 19 (4, 1988): 589-606.

Holmstrom, Bengt, "Moral Hazard and Observability," Bell Journal of Economics $10(1,1979): 74-91$.

Moral Hazard in Teams," Bell Journal of Economics 13 (2, 1982a):

$324-340$

"Managerial Incentive Problems - A Dynamic Perspective," in Essays

in Economics and Management in Honour of Lars Wahlbeck (Helsinki:

Swedish School of Economics), $1982 \mathrm{~b}$.

Holmstrom, Bengt, and Paul Milgrom, "Aggregation and Linearity in the

Trovision of Intertemporal Incentives," Econometrica 55 (2, 1987):

$303-328$

"Multi-Task Principal-Agent Problems," Yale School of

Organization and Management, 1989.

Jensen, Michael C., "Takeovers: Their Causes and Consequences, "Journal of Economic Perspectives $2(1,1988): 21-48$.

Jensen, Michael C., and Kevin J. Murphy, "Performance Pay and Top-Management Incentives," Journal of Political Economy 98 (2, 1990): 225-264.

Jensen, Michael C., and Richard S. Ruback, "The Market for Corporate Control: The Scientific Evidence," Journal of Flnancial Economics 11 $(2,1983): 5-50$.

Kaplan, Steven, "The Effect of Management Buyouts on Operating Performance and Value," Journal of Flnancial Economics $24(1,1989): 217-254$ 
Kokkelenberg, Edward C., "The Behavioral Objectives of Firms and Executive Compensation," Department of Economics, State University of New York at Binghamton, 1988 .

Kostiuk, Peter F., "Firm Size and Executive Compensation," The Journal of human Resources 25 ( 1,1989$)$ : 90-105.

, "Executive Ability, Corporate Performance and Managerial Income," Center for Naval Analysis, January, 1986.

Lambert, Richard A., and David F. Larcker, "Golden Parachutes, Executive Decision-Making and Shareholder Wealth," Journal of Accounting and Economics 7 (2, 1985): 179-204. , "An Analysis of the Use of Accounting and Market Measures of Performance in Executive Contracts, "Journal of Accounting Research 25 (Supplement, 1987): 85-123.

Lambert, Richard A.; David F. Larcker, and Keith Weigelt, "Tournaments and the Structure of Organizational Incentives, "Wharton School, University of Pennsylvania, 1989.

Lazear, Edward P., "Why is There Mandatory Retirement?" Journal of Political Economy $87(6,1979): 1261 / 84$.

\footnotetext{
"Salaries and Piece Rates," Journal of Business 59 (3, 1986): $405-431$.

- "Pay, Inequality and Industrial Politics," Journal of Political
} Economy 97 (3, 1989): 561-580.

Lazear, Edward P., and Sherwin Rosen, "Rank Order Tournaments as Optimum Labor Contracts," Journal of Polltical Economy 89 (5, 1981): $841-874$. Leonard, Jonathan S., "Executive Pay and Firm Performance," Industrial and Labor Relations Review 43 (3, 1990): 13s-29s. 
Levinthal, Daniel, "A Survey of Agency Models of Organizations," Institute for Mathematical Studies in Social Science, Stanford University, 1984. Lewellen, Wilbur G., Executive Compensation in Large Industrial Corporations (New York: Columbia University Press for the National Bureau of Economic Research), 1968.

Lewellen, Wilbur G., and Blaine Huntsman, "Managerial Pay and Corporate Performance," American Economic Review 60 (4, 1970): 710-720.

Lichtenberg, Frank R., and Donald Siegel, "Productivity and Changes in Ownership of Manufacturing Plants," in M.N. Baily and C. Winston (eds.), Brookings Papers in Economic Activity, Volume 3 (Washington, D.C.: Brookings Institution) 1987, pages 643-673. "The Effects of Leveraged Buyouts on Productivity and Related Aspects of Firm Behavior," National Bureau of Economic Research Working Paper No. 3022, 1989.

Manne, Henry G., "Mergers and the Market for Corporate Control," Journal of Political Economy 73 (2, 1965): 110-120.

Marris, Robin, "A Model of the Managerial Enterprise," Quarterly Journal of Economics $77(2,1963): 185-209$.

Masson, Robert, "Executive Motivations, Earnings and Consequent Equity Performance," Journal of Political Economy 79 (6, 1971): 1278-1292. McGuire, Joseph W.; John S.Y. Chiu and Alvar O. Elbing, "Executive Incomes, Sales and Profits," American Economic Review 52 (4, 1962): $753-761$. McLaughlin, Kenneth J., "Aspects of Tournament Models: A Survey," in Research in Labor Economics, Vol. 9 (1988): 225-256. Meeks, Geoffrey, and Geoffrey whittington, "Director's Pay, Growth and Profitability," Journal of Industrial Economics 24 (1, 1975): 1-14. 
Milgrom, Paul, "Employment Contracts, Influence Activities and Efficient Organizational Design," Journal of Political Economy $96(1,1988): 42$ 60 .

Miller, Fredrick H., Jr., "Wages and Establishment Size," Ph.D. dissertation, University of Chicago, 1982.

Miller, Merton H., and Myron S. Scholes, "Executive Compersation, Taxes and Incentives," in W.F. Sharpe and C.M. Cootner (eds.), Essays in Honor of Paul Cootner (Englewood Cliffs, :TJ: Prentice-Hal1), 1982.

Mirrlees, James A., "The Optimal Structure of Incentives and Authority within an Organization," Bell Journal of Economics 7 (Spring, 1976): $105-131$

Mookherjee, Dilip, "Rank Order Competition and Incentives: An Organizational Perspective," Stanford University, 1989.

Morck, Randal1; Andrei Shleifer and Robert W. Vishny, "Management Ownership and Market Valuation," Journal of Financial Economics $20(, 1988 a)$ : $293-315$.

"Alternative Mechanisms for Corporate Control," National Bureau of Economic Research, 1988.

Murphy, Kevin J., "Corporate Performance and Managerial Remuneration," Journal of Accounting and Economics 7 (2, 1985): 11-42.

- "Incentives, Learning and Compensation: A Theoretical and Empirical Investigation of Managerial Labor Contracts," Rand Journal of Economics $17(2,1986): 59-76$.

O'Reilly, C.; Brian Main, and G. Crystal, "CEO Compensation as Tournament and Social Comparison: A Tale of Two Theories," Administrative Science Quarterly $33(3,1988): 257-274$. 
Radner, Roy, "Repeated Principal-Agent Games with Discounting, "Econometrica $53(5,1985): 1173-1198$.

Reder, Melvin W., "The Size Distribution of Earnings," in J. Marchal and B. Ducros (eds.), the Distribution of National Income (London: Macmillan), 1968.

Roberts, Donald R., "A General Theory of Executive Compensation Based on Statistically Tested Propositions," Quarterly Journal of Economics 70 $(3,1956)$ :

Rosen, Sherwin, "The Economics of Superstars," American Economic Review 71 (5. 1981): $845 \cdot 858$.

, "Authority, Control and the Distribution of Earnings, "Rand Journal of Economics $13(2,1982)$ : $311-323$.

, "Prizes and Incentives in Elimination Tournaments, "American Economic Review 76 (4, 1986): 701.715.

Rosenbaum, James, Career Mobility in a Corporate Hlerarchy (New York: Academic Press), 1984.

Shleifer, Andrei, and Lawrence Summers, "Breach of Trust in Hostile Takeovers,: in Alan J. Auerback (ed.), Corporate Takeovers; Causes and Consequences, (Chicago: University of Chicago Press for the National Bureau of Economic Research), 1988.

Sicherman, Nachum and Oded Galor, "A Theory of Career Mobility," Journal of Polltical Economy 98 ( 1,1990$): 169-192$.

Stiglitz, Joseph E., "Incentives, Risk and Information: Notes toward a Theory of Hierarchy," Bell Journal of Economics 6 (Autumn, 1975): 552.579 .

Telser, Lester G., "A Theory of Self-Enforcing Agreements, " Journal of Business $53(1,1980): 27-44$. 
Tirole, Jean, "Hlerarchies and Bureaucracies: On the Role of Collusion in Organizations, " Journal of Law. Economics, and Organization 2 (2, 1986): 181-214.

Tosi, H., and L. Gomez-Mejia, "The Decoupling of CEO Pay and Performance: An Agency Theory Perspective, "Administrative Science Quarterly 34 (2, 1989):

Vancil, Richard F., Passing the Baton: Managing The Process of CEO

Succession, (Boston: Harvard Business School Press), 1987.

Williamson, Oliver, The Economic Institutions of Capitalism (New York: Free Press), 1985.

Winn, Daryl N., and John D. Shoenhair, "Compensation-Based (Disincentives) for Revenue-Maximizing Behavior," Review of Economics and Statistics 70 $(1,1988): 154-158$. 


\section{FOOTNOTE}

*I am indebted to the National Science Foundation for financial

support. Many people have contributed helpful comments, criticism and

discussion, including discussants Bengt Holmstrom and Larry Lau; colleagues

Gary Becker, Gene Fama and Edward Lazear; and contributors to the

literature, especially Kevin J. Murphy, Robert Gibbons, and Edward Glaeser.

I take responsibility for interpretations and errors. 